\title{
Breastfeeding and nutrition to 2 years of age and risk of childhood acute lymphoblastic
} leukemia and brain tumors

Authors: Kathryn R. Greenop ${ }^{1}$, Helen D. Bailey ${ }^{1,2}$, Margaret Miller ${ }^{3}$, Rodney J. Scott ${ }^{4,5,6}$, John Attia $^{4,7}$, Lesley J. Ashton ${ }^{8,9}$, Peter Downie ${ }^{10,11}$, Bruce K. Armstrong ${ }^{12,13}$, Elizabeth Milne ${ }^{1}$.

\section{Author Affiliations:}

${ }^{1}$ Telethon Kids Institute, University of Western Australia, Perth, Western Australia, Australia.

${ }^{2}$ Section of Environment and Radiation, International Agency for Research on Cancer, Lyon, France.

${ }^{3}$ Child Health Promotion Research Centre, School of Exercise and Health Sciences, Edith Cowan University, Mount Lawley, Western Australia, Australia.

${ }^{4}$ Hunter Medical Research Institute, John Hunter Hospital, New South Wales, Australia.

${ }^{5}$ School of Biomedical Sciences and Pharmacy, Faculty of Health, University of Newcastle, Newcastle, New South Wales, Australia.

${ }^{6}$ Hunter Area Pathology Service, HNEHealth, Newcastle, New South Wales, Australia.

${ }^{7}$ School of Medicine and Public Health, Faculty of Health, University of Newcastle, Newcastle, New South Wales, Australia.

${ }^{8}$ Research Portfolio, University of Sydney, Sydney, Australia

${ }^{9}$ School of Women’s and Children's Health, Faculty of Medicine, University of New South Wales, Sydney, Australia.

${ }^{10}$ Children's Cancer Centre, Royal Children's Hospital, Parkville, Victoria, Australia.

${ }^{11}$ Monash Children's Hospital, Southern Health, Melbourne, Victoria, Australia

${ }^{12}$ Sydney School of Public Health, University of Sydney, Sydney, New South Wales, Australia

${ }^{13}$ Sax Institute, Haymarket, New South Wales, Australia

\section{Corresponding author}

Elizabeth Milne, Telethon Kids Institute

PO Box 855 WEST PERTH 6872 Western Australia

Telephone: + 61894897756

Fax: +61 894897700 Email: Liz.Milne@telethonkids.org.au

Text Word count: 3351

Table/Figure count: 4 main tables; 4 supplemental tables

Reference count: 30 


\begin{abstract}
(199 words)
\end{abstract}
Acute lymphoblastic leukemia (ALL) and childhood brain tumors (CBT) are two of the most common forms of childhood cancer, but little is known of their etiology. In two nationwide case-control studies we investigated whether breastfeeding, age of food introduction, or early diet are associated with the risk of these cancers. Cases aged 0-14 years were identified from Australian pediatric oncology units between 2003 and 2007 (ALL) and 2005 and 2010 (CBT) and population-based controls through nationwide random-digit dialling. Mothers completed questionnaires giving details of infant feeding up to the age of two years. Data from 322 ALL cases, 679 ALL controls, 299 CBT cases and 733 CBT controls were analysed using unconditional logistic regression. Breastfeeding was associated with a reduced risk of ALL (OR 0.52, 95\% CI: 0.32, 0.84), regardless of duration. Introduction of artificial formula within 14 days of birth was positively associated with ALL (OR 1.57, 95\% CI: 1.03, 2.37), as was exclusive formula feeding to 6 months (OR 1.81, 95\% CI: 1.07, 3.05). No associations were seen between breastfeeding or formula use and risk of CBT. Our results suggest that breastfeeding and delayed introduction of artificial formula may reduce the risk of ALL but not CBT.

Keywords: child; leukemia; brain tumors, breastfeeding; infant diet; formula feeding; epidemiological 


\section{Introduction}

Little is known about the causes of acute lymphoblastic leukaemia (ALL) or childhood brain tumors (CBT) which are, respectively, the first and second most common childhood cancers in the western world.

The majority of ALL cases are diagnosed before five years of age (1) which suggests that early life factors may play a role. Early exposure to infection is important for normal development of the immune system and delayed exposure may result in a rare response that triggers ALL (2). Breastfeeding may play an important part in normal immune system development as it involves the transmission of viruses and bacteria (2), thus priming the immune system. Breast milk also contains antibodies, providing passive immunity from acute infection during early life (2). Due to these advantages for the infant, the current recommendation is for infants to be exclusively breastfed for the first six months of life $(3,4)$. The association between breastfeeding and ALL has been the focus of three meta-analyses in the last decade (5-7) and all found an overall inverse association, but were cautious about attributing causation. Since these findings were published, two large studies - the Northern California Childhood Leukemia Study (NCCLS) and the Cross Canada Childhood Leukemia Study - reported no association between breastfeeding and $\operatorname{ALL}(8,9)$.

For CBT, there is little evidence that breastfeeding plays a protective role, with six studies finding no association (10-15) and only one finding an inverse association (16). Another recent study found a protective association between breastfeeding and the risk of childhood cancer (OR for six months or more 0.5, 95\% CI: 0.2-0.9), but did not separate cancer types (17). Only 34\% of cases had ALL and 14\% had CBT, making the interpretation of these findings with respect to specific cancer types difficult.

Less research has focussed on whether the child's nutritional intake during infancy is associated with risk of ALL or CBT. Investigations of early dietary patterns before the age of two years and risk of ALL have been undertaken by the NCCLS $(8,18)$ and a Texan group $(19)$. While no association was seen with the age of introduction of solid foods (8), regular consumption of bananas, oranges or orange juice in the first two years appeared to reduce the risk of disease (18). These results suggest that some factor, such as vitamin $C$ or potassium, in the first few years of life may reduce the risk of ALL. Schraw and colleagues found that longer duration of formula feeding and delayed introduction to solid foods was associated with an increased risk of ALL (19). For CBT, one study reported a protective association with fruit consumption in the 
first year of life (20), and two other studies reported no associations with either food or vitamin intake in the first year of life (21) or the age at which solid foods were introduced (11).

The Australian Study of Acute Lymphoblastic Leukaemia (Aus-ALL) and the Australian Study of Childhood Brain Tumors (Aus-CBT) aimed to investigate genetic, dietary and environmental risk factors for ALL and CBT respectively. The aim of the current analysis was to conduct a detailed investigation of breastfeeding duration and timing of food introduction, together with other aspects of the child's nutritional intake up to the age of two years.

\section{Material and Methods}

Aus-ALL and Aus-CBT have been described previously (22, 23). Briefly, they were both national, population-based case-control studies, conducted between 2003 and 2006 and 2005 and 2010 respectively. Eligibility criteria were: diagnosis before 15 years of age and the availability of a biological mother with sufficient English to complete the questionnaires. Case families were identified and recruited through all ten pediatric oncology centers in Australia. ALL cases were eligible if they had been diagnosed between $1^{\text {st }}$ July 2003 and $31^{\text {st }}$ December 2006 and had reached remission. CBT cases were eligible if they were diagnosed between 2005 and 2010. Controls for both studies were recruited by random digit dialing and were frequency matched to cases by age, sex and State of residence in an approximate ratio of 3:1. Aus-ALL controls were recruited between 2003 and 2006 and CBT controls were recruited between 2007 and 2010 . Aus-ALL controls recruited in 2005 and 2006 were also used as controls for Aus-CBT. Both studies had Human Research Ethics Committee approval from all participating hospitals.

\section{Dietary assessment}

Mothers were asked to complete a questionnaire about their child's nutritional intake up to the age of two years; if the child was younger than 2 years mothers completed the relevant parts of the questionnaire up to diagnosis (or questionnaire completion for controls). Mothers were asked whether the child had ever been breastfed and for how long, and about the use of infant formulas, the main types of milk given, and the age of introduction of a range of foods. This information was used to calculate the length of exclusive breastfeeding. To assign the age at which formula feeding was commenced, we considered only formulas given for one month or longer. This was done to exclude short or atypical uses of formula likely to have had little influence on the infant's overall nutrition. Mothers were also asked to complete a food frequency table consisting of 28 food items about their children's diet between the ages of one and two years. Dietary folate intake was estimated by combining nutrient data from AUS-NUT 
07 (24) and serving sizes based on those observed among 16-24 month old children in an Australian study (25). Voluntary fortification of individual foods (breakfast cereals; breads; fruit juices; yoghurts and milk) with folic acid was recorded and accounted for; wheat flour was mandatorily fortified from September 2009 (26).

Information was collected from manufacturers and product labels about the constituents of all supplements taken by the child up to two years of age. This information was used to assess whether the child had had a supplement containing multivitamins, folic acid, Vitamins A, B6, $\mathrm{B} 12$, or $\mathrm{C}$ or iron.

\section{Subtype classification}

We obtained information about immunophenotype and cytogenetic subtypes of ALL cases from the treating clinicians. The latter were determined using metaphase cytogenetics and fluorescence in situ hybridization screening. CBT subtypes were recorded by the treating clinician, and categorized independently by two pediatric oncologists as previously described (23).

\section{Statistical analysis}

For breastfeeding duration, we excluded children under 7 months of age at censoring date, as they could not contribute to the highest duration category. Two measures of 'any breastfeeding' (regardless of duration) were used: one which included all available children and the other with the above age restriction to allow comparison with the duration variables. The analysis of early food introduction included only children aged over 12 months as these were considered to be of a sufficient age to have been introduced to most common foods.

Correlations between the age of introduction of individual foods were evaluated with Pearson's correlation coefficients. Age at initiation of formula feeding (for more than one month) was divided into groups based on tertiles among controls who received formula before six months. The information about the age at which specific solid foods were introduced was categorised into two groups, based on the distribution among the controls. Children who had never had that food before the age of two years were included in a separate group. The frequency of intake of key food groups was examined by collapsing clusters of nutritionally similar foods from the questionnaire, then dividing into frequency groups based on the tertile distribution among controls. As a large proportion of children were introduced to some foods at similar times, or had similar frequencies of food intake, some of the tertile-based groups were not equal. 
Odds ratios (OR) and 95 percent confidence intervals (95\% CI) were estimated using unconditional logistic regression in SPSS (IBM SPSS for Windows, version 20.0, Armonk, NY, IBM Corp, 2011). All models were adjusted for the study matching factors - age at diagnosis in months, sex and State of residence. Variables considered a priori to be potential confounders of the association between early life nutrition and the risk of ALL/CBT (ethnicity, maternal age at the child's birth, birth order, birth weight, family income and maternal education) were assessed for inclusion in the models. Variables that met the empirical definition of confounding (independently associated with both the exposure and the outcome) were included in the final models. As breastfeeding was found to be associated with ALL, it was also included in the final models for food exposures, as was proportion of optimum birth weight (POBW) (27). The final models for ALL analyses contained the matching factors, maternal age at the child's birth, birth order and maternal education, breastfeeding status and POBW. As having a birth defect was associated with both early life nutrition and risk of ALL, these children were excluded from ALL analyses. For CBT analyses, the potential confounders varied by exposure variable - those included in the final models are shown in the footnotes to tables.

We also analysed the breastfeeding data by immunophenotype and cytogenetic subtype (for ALL) and by tumor subtype (for CBT) for groups with more than 50 cases.

\section{Results}

We were notified of 519 eligible ALL cases between 2003 and 2007; parents of 416 (80.2\%) consented to participate in the study, and the infant feeding questionnaire was completed and returned by 341 mothers (82.0\%). Between 2005 and 2010, 730 eligible CBT cases were identified, of whom 568 (78\%) were invited and 374 (66\% of invited, 51\% of eligible) consented to take part. Of these, 299 (80\% recruited) case mothers completed an infant feeding questionnaire.

Between 2003 and 2010, 4,703 families eligible to be controls were identified, of whom 3,012 (64\%) agreed to participate. In accordance with requirements for age and sex frequencymatching, we recruited 2,165 of these children to the study. Of these, 1,112 control mothers (51\% of those recruited in both studies) completed an infant feeding questionnaire.

For ALL, 19 case and 23 control children with birth defects were excluded, leaving 322 cases and 679 controls for analysis. For CBT, 299 cases and 733 controls were available for analyses (Table 1). Due to small amounts of missing exposure or covariate data, the numbers available for analysis of different infant feeding factors varied. 


\section{Demographics}

The demographic characteristics of cases and controls were generally similar, with some exceptions (Table 1). ALL case children were more likely to be first born than control children (50.5\% versus $41.1 \%$ ) while control mothers were more likely to have a college/university education and to have been aged 35 years or older when the child was born. CBT controls were more likely to be of European ethnicity.

\section{Breastfeeding and formula feeding}

'Any breastfeeding' results were similar whether we included all children or only those aged 7 months or more - the latter measure is reported henceforth. For ALL, the OR for having been breastfed was 0.52 (95\% CI: 0.32, 0.84). However, this association was not stronger with increased duration of breastfeeding or exclusive breastfeeding. There was no association with formula feeding overall, and ALL was only associated with age at commencement of formula if it was introduced within 14 days of birth (OR: 1.57, 95\% CI: 1.03, 2.37). In addition, the OR for exclusive use of formula to six months of age was 1.81 (95\% CI: 1.07, 3.05) (Table 2).

For CBT, the ORs of any breastfeeding, breastfeeding duration, age starting on formula, and infant feeding method were all close to unity. The main type of milk given to the child between six months and one year and between one and two years of age did not appear to be associated with the risk of ALL or CBT (Table 2).

The ORs for breastfeeding by ALL subtype were all below the null, similar to the overall OR, apart from the ETV6-Runx-1 t(12;21) subtype (Supplementary Table 1). The highest OR for any formula feeding was in the hyperdiploidy subgroup. The ORs for breastfeeding and formula feeding among CBT subtypes (low-grade gliomas and embryonal tumors) were generally null, similar to the overall results. Most estimates were imprecise and potentially unstable due to small numbers of cases.

\section{Introduction of Foods}

The age of introduction of solid foods and fruit juice were all significantly inter-correlated (Supplemental Table 2), making the interpretation of findings for the introduction of individual foods difficult. Using ' $\leq 4$ months' as the reference group, the OR for starting food (any type) after four months of age was 1.40 (95\% CI: 1.03, 1.90) for CBT. There was a suggestion that those who started vegetables later had an increased risk of ALL and CBT, and that those who started eggs later had a reduced risk of ALL (Table 3). 
The frequency of intake of different food groups between the ages of one and two years is shown in Table 4. For ALL, the OR for more than 1.1 serves/day of meat/chicken/fish/eggs was 1.39 (95\% CI: 0.98, 1.96, $\left.P_{\text {trend }}=0.07\right)$. There were no associations evident between food group intake and risk of CBT.

\section{Dietary folate and supplemental vitamins}

There was no association between dietary folate intake between one and two years of age and risk of ALL or CBT (Supplemental Table 3). Few cases or controls had any vitamins or other supplements before two years of age, and no association was seen for ALL or CBT (Supplementary Table 4).

\section{Sensitivity analyses}

We repeated the analyses for breastfeeding excluding women who breastfed for 14 days or less, and the results for both ALL and CBT remained unchanged (data not shown).

Since controls recruited in 2005 and 2006 were used in the analyses for both ALL and CBT, we investigated whether the results differed when these controls were randomly allocated to either analysis (that is, independent controls used in each analysis); none of the results were materially different from those presented (data not shown).

\section{Discussion}

We collected data on dietary intake using detailed infant feeding questionnaires, which allowed us to determine breastfeeding duration and exclusivity, as well as other details of diet during infancy that have not been previously examined. Breastfeeding was associated with a reduced risk of ALL, but there was no evidence of a dose-dependent relationship with duration of breastfeeding or exclusive breastfeeding. Commencement of formula feeding (of $\geq 1$ month's duration) was associated with an increased risk of ALL when started within 14 days of birth. There was no association between CBT risk and breastfeeding or use of infant formula.

Our findings for breastfeeding and ALL are consistent with three previous meta-analyses (5-7), although our OR $(0.52,95 \%$ CI: $0.32,0.86)$ was lower than the pooled ORs in these reports. Our null finding for breastfeeding and CBT risk is similar to most previous studies $(10-15,28)$.

It has been proposed that B-cell ALL may be caused by an abnormal response to infection in children who have not been exposed to infectious agents early in life (2). It is possible that breastfeeding could guard against childhood ALL by providing passive immunity against infection whilst the postnatal immune system is developing, by the ingestion of maternal antibodies in breast milk (2). If the associations we observed were causal, our ORs suggest a 
threshold effect rather than a dose-dependent effect; that is, even a brief period of breastfeeding may confer protection against ALL. A recent study reported an association between duration of formula feeding and risk of ALL, and the authors speculated that this may be because formula feeding increases insulin-like growth factor-1 levels more than breastfeeding, which in turn accelerates growth and causes proliferative stress, leading to higher ALL risk (19). These authors further hypothesized that earlier age of introduction to infant formula (which could not be investigated in their data) may be associated with increased risk of ALL; we found an increased risk among infants started on formula within 14 days of birth (about half of these were also breastfed to some extent) as well as infants exclusively fed formula to six months of age. Since initiation of breastfeeding and early use of infant formula are inversely correlated with each other, we cannot be sure whether the mechanism (if any) driving these associations is related to a benefit from breastfeeding or a detrimental effect of formula or both.

There was some suggestion of an association between frequent consumption of meat/chicken/fish/eggs between the ages of one and two years and risk of ALL (but not CBT). Given the weakness of the association, it could be due to chance. The only previous study examining the association between food intake before two years of age and risk of ALL specifically examined cured meats and found no association (18).

Unlike our null finding, one previous study (19) reported a modest increased risk for ALL associated with the delayed introduction to solids. We did observe a positive association between introduction to food after four months and risk of CBT; the one other study to investigate this relationship in CBT found no association (11). We saw no associations between ALL or CBT and dietary folate intake or use of vitamin supplements.

It has been proposed that the inverse association between breastfeeding and ALL seen in many observational studies could be caused by selection bias and/or recall bias (5-7). However, despite the relatively low participation fraction among controls and the slightly higher socioeconomic status of controls relative to cases in our study, the proportion of ALL and CBT controls who were ever breastfed (94\% and 93\% respectively) were similar to the proportion in the 'Growing up in Australia' 2004 population cohort (92\%) (29), suggesting that they were representative of the target population in this respect. In addition, when we stratified our results by education level, the ORs for breastfeeding were similar in both high and low education groups (interaction term $P$-value 0.72 ). Therefore, we consider it unlikely that the inverse association we observed for breastfeeding is entirely attributable to selection bias. 
Exposure misclassification is also possible, especially when mothers are asked to recall details of infant feeding many years in the past. However, a study of recall of breastfeeding initiation and duration in Norway (where breastfeeding rates are high) showed very good recall $(\kappa=0.85)$ up to 20 years after the event (30). Recall bias is also possible if case mothers report exposures differently from control mothers; however, it seems unlikely that this would occur for ALL but not CBT. Thus, we believe that recall bias is unlikely to account for the inverse relationship we observe for breastfeeding and ALL.

We were unable to accurately quantify portion sizes for food group intake - we were only able to assess the frequency that children received each food. Since portion sizes change rapidly with age during infancy, and assessment was based on intake frequency, considerable measurement error in the total quantity consumed may have occurred; however, such error is likely to be nondifferential and would have biased the ORs to the null.

In Aus-ALL, only 4 cases ( $<1 \%$ of those identified) did not reach remission. Therefore, it is unlikely that our findings for ALL were affected by survival bias. In Aus-CBT, however, approximately 9\% of identified cases had died (and were therefore ineligible for study participation) and $10 \%$ of eligible cases were considered by their doctor to be too unwell to be invited to take part. If breastfeeding or infant nutrition were associated with survival or severity of CBT, our findings may be biased. However, we are unaware of any evidence that this may be the case, and it would be difficult to predict what direction such bias could take. Our findings may only be generalizable to less severe CBT cases.

In conclusion, our results suggest that breastfeeding may reduce the risk of ALL, and that early introduction of regular use of artificial formula may increase the risk of ALL. If causal, these results could be due to the nutritional/immune effects of breast milk or the impact of formula on growth, or a combination of these factors. We saw no association between breastfeeding or formula use and risk of CBT, while there was weak evidence that the introduction of foods later than four months of age may be associated with an increased risk.

\section{Acknowledgements}

The Aus-ALL and Aus-CBT consortia conducted the study and the Telethon Kids Institute (formally the Telethon Institute for Child Health Research; TICHR), University of Western Australia, was the coordinating centre. Bruce Armstrong (Sydney School of Public Health), Elizabeth Milne (TICHR), Frank van Bockxmeer (University of Western Australia), Rodney Scott (University of Newcastle), Lin Fritschi (WA Institute for Medical Research), Lesley Ashton (Children's Cancer Institute Australia (CCIA)), Nicholas de Klerk (TICHR), Caroline Bower (TICHR), Margaret Miller (Edith Cowan University), John Attia (University of 
Newcastle), Michelle Haber (CCIA), Murray Norris (CCIA), Judith Thompson (WA Cancer Registry), and Peter Dallas and Ursula Kees (TICHR) were the research investigators.

The authors acknowledge the contribution made by our clinical co-investigators who recruited and cared for study patients at each participating hospital: Catherine Cole and Nicholas Gottardo (Princess Margaret Hospital, TICHR); John Heath and Elizabeth Smibert (Royal Children's Hospital, Melbourne); Peter Downie (Monash Medical Centre, Melbourne); Liane Lockwood, Tim Hassall and Ross Pinkerton (Royal Children’s Hospital Brisbane); Maria Kirby (Women’s and Children's Hospital, Adelaide); Stewart Kellie and Luciano dalla Pozza (Children's Hospital at Westmead); Frank Alvaro (John Hunter Hospital, Newcastle); Glenn Marshall and Richard Cohn (Sydney Children’s Hospital) and John Daubenton (Royal Hobart Hospital).

The authors also acknowledge the Clinical Research Associates at each hospital, and the study coordinators: Jackie Mansour, Somer Dawson, Tamika Heiden, and Helen Bailey, and Peter Cosgrove for programming the dietary folate calculations.

Funding: The National Health and Medical Research Council (NHMRC) funded Aus-ALL (Grant number: 254539) and Aus-CBT (Grant number: 404089). Elizabeth Milne was supported by an NHMRC Fellowship. Support for Rodney Scott was in part from NBN Children's Cancer Research Fund. 


\section{References}

1. Parkin DM, Kramarova E, Draper GJ, Masuyer E, Michaelis J, et al.: International Incidence of Childhood Cancer. IARC Scientific Publication No. 144, vol. II, 450, 1998.

2. Greaves MF: Aetiology of acute leukaemia. Lancet 349, 344-349., 1997.

3. National Health and Medical Research Council (Australia): Dietary guidelines for children and adolescents in Australia : incorporating the Infant feeding guidelines for health workers. Canberra: NHMRC, 2003.

4. World Health Organisation: Report of the expert consultation on the optimal duration of breastfeeding. Geneva: World Health Organisation

[http://www.who.int/nutrition/publications/optimal_duration_of_exc_bfeeding_report_en g.pdf], 2002.

5. Beral V, Fear NT, Alexander F, Appleby P: Breastfeeding and childhood cancer. Br J Cancer 85, 1685-1694, 2001.

6. Kwan ML, Buffler PA, Abrams B, Kiley VA: Breastfeeding and the risk of childhood leukemia: a meta-analysis. Public Health Rep 119, 521-535, 2004.

7. Martin RM, Gunnell D, Owen CG, Smith GD: Breast-feeding and childhood cancer: A systematic review with metaanalysis. Int J Cancer 117, 1020-1031, 2005.

8. Kwan ML, Buffler PA, Wiemels JL, Metayer C, Selvin S, et al.: Breastfeeding patterns and risk of childhood acute lymphoblastic leukaemia. Br J Cancer 93, 379-384, 2005.

9. MacArthur AC, McBride ML, Spinelli JJ, Tamaro S, Gallagher RP, et al.: Risk of childhood leukemia associated with vaccination, infection, and medication use in childhood: the Cross-Canada Childhood Leukemia Study. Am J Epidemiol 167, 598-606, 2008.

10. Mallol-Mesnard N, Menegaux F, Lacour B, Hartmann O, Frappaz D, et al.: Birth characteristics and childhood malignant central nervous sytem tumors: the ESCALE study (French Society for Childhood Cancer). Cancer Detect Prev 32, 79-86, 2008.

11. Harding NJ, Birch JM, Hepworth SJ, McKinney PA: Breastfeeding and risk of childhood CNS tumours. Br J Cancer 96, 815-817, 2007.

12. Hardell L, Dreifaldt AC: Breast-feeding duration and the risk of malignant diseases in childhood in Sweden. Eur J Clin Nutr 55, 179-185, 2001.

13. Schuz J, Kaletsch U, Kaatsch P, Meinert R, Michaelis J: Risk factors for pediatric tumors of the central nervous system: results from a German population-based case-control study. Med Pediatr Oncol 36, 274-282, 2001.

14. Smulevich VB, Solionova LG, Belyakova SV: Parental occupation and other factors and cancer risk in children: 1 . Study methodology and non-occupational factors. Int J Cancer 83, 712-717, 1999.

15. McKinney PA, Juszczak E, Findlay E, Smith K, Thomson CS: Pre- and perinatal risk factors for childhood leukaemia and other malignancies: a Scottish case control study. $\mathrm{Br} \mathrm{J}$ Cancer 80, 1844-1851., 1999.

16. Davis MK, Savitz DA, Graubard BI: Infant feeding and childhood cancer. Lancet 2, 365368, 1988.

17. Ortega-Garcia JA, Ferris-Tortajada J, Torres-Cantero AM, Soldin OP, Torres EP, et al.: Full breastfeeding and paediatric cancer. J Paediatr Child Health 44, 10-13, 2008.

18. Kwan ML, Block G, Selvin S, Month S, Buffler PA: Food consumption by children and the risk of childhood acute leukemia. Am J Epidemiol 160, 1098-1107, 2004.

19. Schraw JM, Dong YQ, Okcu MF, Scheurer ME, Forman MR: Do longer formula feeding and later introduction of solids increase risk for pediatric acute lymphoblastic leukemia? Cancer Causes Control 25, 73-80, 2014.

20. McCredie M, Maisonneuve P, Boyle P: Perinatal and early postnatal risk factors for malignant brain tumours in New South Wales children. Int J Cancer 56, 11-15, 1994. 
21. Bunin GR, Kuijten RR, Boesel CP, Buckley JD, Meadows AT: Maternal diet and risk of astrocytic glioma in children: a report from the Childrens Cancer Group (United States and Canada). Cancer Causes Control 5, 177-187, 1994.

22. Bailey H, Milne E, de Klerk N, Fritschi L, Bower C, et al.: Representativeness of child controls recruited by random digit dialing. Paediatr Perinat Epidemiol 24, 293-302, 2010.

23. Milne E, Greenop KR, Bower C, Miller M, van Bockxmeer FM, et al.: Maternal use of folic acid and other supplements and risk of childhood brain tumors. Cancer Epidemiol Biomarkers Prev 21, 1933-1941, 2012.

24. Food Standards Australia New Zealand: AUSNUT 2007 - Australian food, supplement and nutrient database for estimation of population nutrient intakes. Canberra: FSANZ, 2008.

25. Webb K, Rutihauser I, Knezevic N: Foods, nutrients and portions consumed by a sample of Australian children aged 16-24 months. Nutr Diet 65, 56-65, 2008.

26. Australia New Zealand Food Standards Code - Standard 2.1.1 - Cereals and Cereal Products - F2009C00811, Amendment No. 111 - 2009 Canberra [http://www.comlaw.gov.au/Details/F2009C00811p]: Commonwealth of Australia 2009.

27. Milne E, Royle JA, de Klerk NH, Blair E, Bailey H, et al.: Fetal growth and risk of childhood acute lymphoblastic leukemia: results from an Australian case-control study. Am J Epidemiol 170, 221-228, 2009.

28. Bunin GR, Buckley JD, Boesel CP, Rorke LB, Meadows AT: Risk factors for astrocytic glioma and primitive neuroectodermal tumor of the brain in young children: a report from the Children's Cancer Group. Cancer Epidemiol Biomarkers Prev 3, 197-204, 1994.

29. Growing up in Australia: the longitudinal study of Australian children. 2006-2007 Annual Report. Melbourne, Australia: Australian Government Department of Families, Housing, Community Servies and Indigenous Affairs and the Australian Institute of Family Studies; Commonwealth of Australia [http://www.growingupinaustralia.gov.au/pubs/ar/ar200607/index.html], 2008.

30. Natland ST, Andersen LF, Nilsen TI, Forsmo S, Jacobsen GW: Maternal recall of breastfeeding duration twenty years after delivery. BMC Med Res Methodol 12, 179, 2012. 
Table 1: Demographic characteristics of cases and controls

\begin{tabular}{|c|c|c|c|c|c|c|c|c|}
\hline \multirow[b]{2}{*}{ Total available } & \multicolumn{3}{|c|}{ ALL } & Controls & $\begin{array}{l}\text { CBT } \\
\text { Case }\end{array}$ & & Con & \\
\hline & $\begin{array}{l}\mathrm{n} \\
322 \\
\end{array}$ & $\%$ & $\begin{array}{l}\mathrm{n} \\
679 \\
\end{array}$ & $\%$ & $\begin{array}{l}\mathrm{n} \\
299 \\
\end{array}$ & $\%$ & $\begin{array}{l}\mathrm{n} \\
733 \\
\end{array}$ & $\%$ \\
\hline \multicolumn{9}{|l|}{ Sex } \\
\hline Boys & 176 & 54.7 & 356 & 52.4 & 177 & 59.2 & 381 & 52.0 \\
\hline Girls & 146 & 45.0 & 323 & 47.6 & 122 & 40.8 & 352 & 48.0 \\
\hline \multicolumn{9}{|l|}{ Age $^{1}$} \\
\hline $0-1$ & 28 & 8.7 & 45 & 6.6 & 48 & 16.1 & 86 & 11.7 \\
\hline $2-4$ & 146 & 45.3 & 287 & 42.3 & 69 & 23.1 & 224 & 30.6 \\
\hline $5-9$ & 93 & 28.9 & 239 & 35.2 & 74 & 24.7 & 190 & 25.9 \\
\hline $10-14$ & 55 & 17.1 & 108 & 15.9 & 108 & 36.1 & 233 & 31.8 \\
\hline \multicolumn{9}{|l|}{ State of residence $^{2}$} \\
\hline NSW/ACT & 100 & 31.1 & 205 & 30.2 & 102 & 34.1 & 220 & 30.0 \\
\hline Queensland & 56 & 17.4 & 142 & 20.9 & 56 & 18.7 & 169 & 23.1 \\
\hline SA/NT & 35 & 10.9 & 63 & 9.3 & 18 & 6.0 & 57 & 7.8 \\
\hline Victoria/Tasmania & 95 & 29.5 & 197 & 29.0 & 83 & 27.8 & 203 & 27.7 \\
\hline Western Australia & 36 & 11.2 & 72 & 10.6 & 40 & 13.4 & 84 & 11.5 \\
\hline \multicolumn{9}{|l|}{ Birth order } \\
\hline 1 & 161 & 50.0 & 279 & 41.1 & 136 & 45.5 & 302 & 41.2 \\
\hline 2 & 93 & 28.9 & 231 & 34.0 & 97 & 32.4 & 267 & 36.4 \\
\hline $3+$ & 68 & 21.1 & 169 & 24.9 & 66 & 22.1 & 164 & 22.4 \\
\hline \multicolumn{9}{|l|}{ POBW $^{3}$} \\
\hline$\leq 113 \%($ mean+1SD $)$ & 269 & 85.1 & 578 & 86.9 & 257 & 89.5 & 628 & 86.6 \\
\hline$>113 \%$ & 47 & 14.9 & 87 & 13.1 & 30 & 10.5 & 97 & 13.4 \\
\hline \multicolumn{9}{|l|}{ Multiple birth } \\
\hline Singleton & 315 & 97.8 & 661 & 97.3 & 289 & 96.7 & 705 & 96.2 \\
\hline Multiple & 7 & 2.2 & 18 & 2.7 & 10 & 3.3 & 28 & 3.8 \\
\hline \multicolumn{9}{|l|}{ In NICU $>2$ weeks $^{4}$} \\
\hline No & 292 & 93.9 & 529 & 94.6 & 250 & 89.9 & 672 & 92.6 \\
\hline Yes & 19 & 6.1 & 30 & 5.4 & 28 & 10.1 & 54 & 7.4 \\
\hline \multicolumn{9}{|l|}{ Child's birth year } \\
\hline $1988-1993 / 90-98$ & 42 & 13.0 & 83 & 12.2 & 85 & 28.4 & 180 & 24.6 \\
\hline $1994-1999 / 98-03$ & 107 & 33.7 & 248 & 36.5 & 122 & 40.8 & 357 & 48.7 \\
\hline $2000-2006 / 04-10$ & 173 & 53.7 & 348 & 51.3 & 92 & 30.8 & 196 & 26.7 \\
\hline \multicolumn{9}{|l|}{ Mother's age at child's birth } \\
\hline$<25$ years & 45 & 14.0 & 59 & 8.7 & 46 & 15.4 & 50 & 6.8 \\
\hline 25 to 34 years & 219 & 68.0 & 459 & 67.6 & 185 & 62.1 & 465 & 63.4 \\
\hline $35+$ years & 58 & 18.0 & 161 & 23.7 & 67 & 22.5 & 218 & 29.7 \\
\hline \multicolumn{9}{|l|}{ Mother's education ${ }^{5}$} \\
\hline Didn’t complete secondary & 87 & 27.0 & 149 & 21.9 & 70 & 23.5 & 126 & 17.2 \\
\hline $\begin{array}{l}\text { Complete secondary or trade } \\
\text { qualification }\end{array}$ & 114 & 35.4 & 243 & 35.8 & 100 & 33.6 & 248 & 33.8 \\
\hline $\begin{array}{l}\text { University/college } \\
\text { Ethnicity }\end{array}$ & 121 & 37.6 & 287 & 42.3 & 128 & 43.0 & 359 & 49.0 \\
\hline European ethnicity & 243 & 75.7 & 528 & 77.8 & 187 & 62.5 & 565 & 77.1 \\
\hline At least 50\% European & 59 & 18.3 & 116 & 17.1 & 71 & 23.7 & 121 & 16.5 \\
\hline $\begin{array}{l}\text { At least } 50 \% \text { non-European } \\
\text { and unknown if } 50 \%\end{array}$ & 12 & 3.7 & 15 & 2.2 & 12 & 4.0 & 22 & 3.0 \\
\hline
\end{tabular}




\section{European}

Indeterminate

8

$2.5 \quad 20$

$2.9 \quad 29$

$9.7 \quad 25$

3.4

${ }^{1}$ Age groups are based on the child's age at the censoring date. For cases, this was the date of diagnosis and for controls it was the date the questionnaire was returned.

${ }^{2}$ ACT, Australian Capital Territory; NSW, New South Wales; NT, Northern Territory; SA, South Australia.

${ }^{3}$ POBW data missing for 6 ALL cases, 14 ALL controls, 12 CBT cases, 8 CBT controls.

${ }^{4}$ Neonatal Intensive Care Unit stay data missing for 11 ALL cases, 120 ALL controls, 21 CBT cases and 7 CBT controls.

${ }^{5}$ Maternal education missing for 1 CBT case.

${ }^{6}$ European $=$ at least 3 European grandparents; 50\% European $=2$ European grandparents; At least 50\% non-European and not known if 50\% European $=2$ non-European grandparents and ethnicity of other 2 grandparents unknown; Indeterminate $=$ no 2 grandparents with the same ethnicity (ie European or non-European) and 2+ grandparents of unknown ethnicity. 
Table 2: Breastfeeding, infant feeding method, and main milks and risk of childhood ALL and CBT.

\begin{tabular}{|c|c|c|c|c|c|c|c|c|c|c|}
\hline & \multicolumn{5}{|l|}{ ALL } & \multicolumn{5}{|c|}{ CBT } \\
\hline & \multicolumn{2}{|c|}{$\begin{array}{l}\text { Cases } \\
n=314\end{array}$} & \multicolumn{2}{|c|}{$\begin{array}{l}\text { Controls } \\
n=663\end{array}$} & \multirow[t]{2}{*}{ OR $(95 \% \text { CI })^{1,2}$} & \multicolumn{2}{|c|}{$\begin{array}{l}\text { Cases } \\
n=278\end{array}$} & \multicolumn{2}{|c|}{$\begin{array}{l}\text { Controls } \\
n=726\end{array}$} & \multirow[t]{2}{*}{ OR $(95 \% \mathrm{CI})^{2,3}$} \\
\hline & $\mathrm{n}$ & $\%$ & $\mathrm{n}$ & $\%$ & & $\mathrm{n}$ & $\%$ & $n$ & $\%$ & \\
\hline \multicolumn{11}{|l|}{ Any breastfeeding (all ages) } \\
\hline No & 35 & 11.1 & 40 & 6.0 & Reference & 24 & 8.6 & 50 & 6.9 & Reference \\
\hline Yes & 279 & 88.9 & 623 & 94.0 & $0.52(0.32,0.86)$ & 254 & 91.4 & 676 & 93.1 & $0.81(0.47,1.38)$ \\
\hline \multicolumn{11}{|l|}{ If $\geq 7$ months of age } \\
\hline No & 35 & 11.4 & 40 & 6.1 & Reference & 24 & 8.9 & 49 & 6.9 & Reference \\
\hline Yes & 273 & 88.6 & 617 & 93.9 & $0.52(0.32,0.84)$ & 246 & 91.1 & 657 & 93.1 & $0.80(0.47,1.37)$ \\
\hline \multicolumn{11}{|l|}{ Duration of breastfeeding $^{4}$} \\
\hline$<3$ months & 65 & 21.1 & 142 & 21.6 & $0.49(0.28,0.86)$ & 59 & 21.9 & 133 & 18.9 & $0.86(0.47,1.56)$ \\
\hline$\geq 3-<6$ months & 45 & 14.6 & 84 & 12.8 & $0.62(0.34,1.12)$ & 37 & 13.7 & 94 & 13.3 & $0.82(0.43,1.58)$ \\
\hline$\geq 6$ months & 163 & 52.9 & 391 & 59.5 & $0.51(0.30,0.84)$ & 150 & 55.6 & 429 & 60.9 & $0.77(0.43,1.58)$ \\
\hline \multicolumn{11}{|l|}{$\begin{array}{l}\text { Duration of exclusive } \\
\text { breastfeeding }\end{array}$} \\
\hline$<3$ months & 98 & 31.8 & 221 & 33.6 & $0.50(0.29,0.84)$ & 80 & 29.9 & 215 & 30.8 & $0.75(0.42,1.34)$ \\
\hline$\geq 3-<6$ months & 125 & 40.6 & 284 & 43.2 & $0.52(0.31,0.87)$ & 106 & 39.6 & 284 & 40.7 & $0.85(0.48,1.50)$ \\
\hline$\geq 6$ months & 50 & 16.2 & 112 & 17.0 & $0.55(0.31,0.99)$ & 58 & 21.6 & 150 & 21.5 & $0.86(0.46,1.59)$ \\
\hline \multicolumn{11}{|l|}{ Any formula feeding } \\
\hline No & 75 & 24.2 & 180 & 27.3 & Reference & 65 & 24.2 & 194 & 27.5 & Reference \\
\hline Yes & 235 & 75.8 & 479 & 72.7 & $1.07(0.78,1.48)$ & 204 & 75.8 & 512 & 72.5 & $1.11(0.79,1.57)$ \\
\hline \multicolumn{11}{|l|}{$\begin{array}{l}\text { Age started formula } \\
\text { (if used } \geq 1 \text { month) }\end{array}$} \\
\hline Never used formula $\geq 1$ month & 75 & 25.6 & 191 & 30.3 & Reference & 69 & 26.3 & 200 & 28.8 & Reference \\
\hline$\geq 6$ months & 60 & 20.5 & 126 & 20.0 & $1.15(0.75,1.75)$ & 61 & 23.3 & 167 & 24.0 & $1.03(0.68,1.57)$ \\
\hline 2-6 months & 56 & 19.1 & 114 & 18.1 & $1.12(0.73,1.71)$ & 55 & 21.0 & 118 & 17.0 & $1.28(0.82,1.98)$ \\
\hline 15 days- 2 months & 27 & 9.2 & 92 & 14.6 & $0.65(0.38,1.10)$ & 31 & 11.8 & 82 & 11.8 & $0.98(0.58,1.64)$ \\
\hline$<15$ days & 75 & 25.6 & 108 & 17.1 & $1.57(1.03,2.37)$ & 46 & 17.6 & 128 & 18.4 & $0.87(0.55,1.38)$ \\
\hline $\begin{array}{l}\text { Infant feeding method } \\
\text { until } 6 \text { months }\end{array}$ & & & & & & & & & & \\
\hline
\end{tabular}




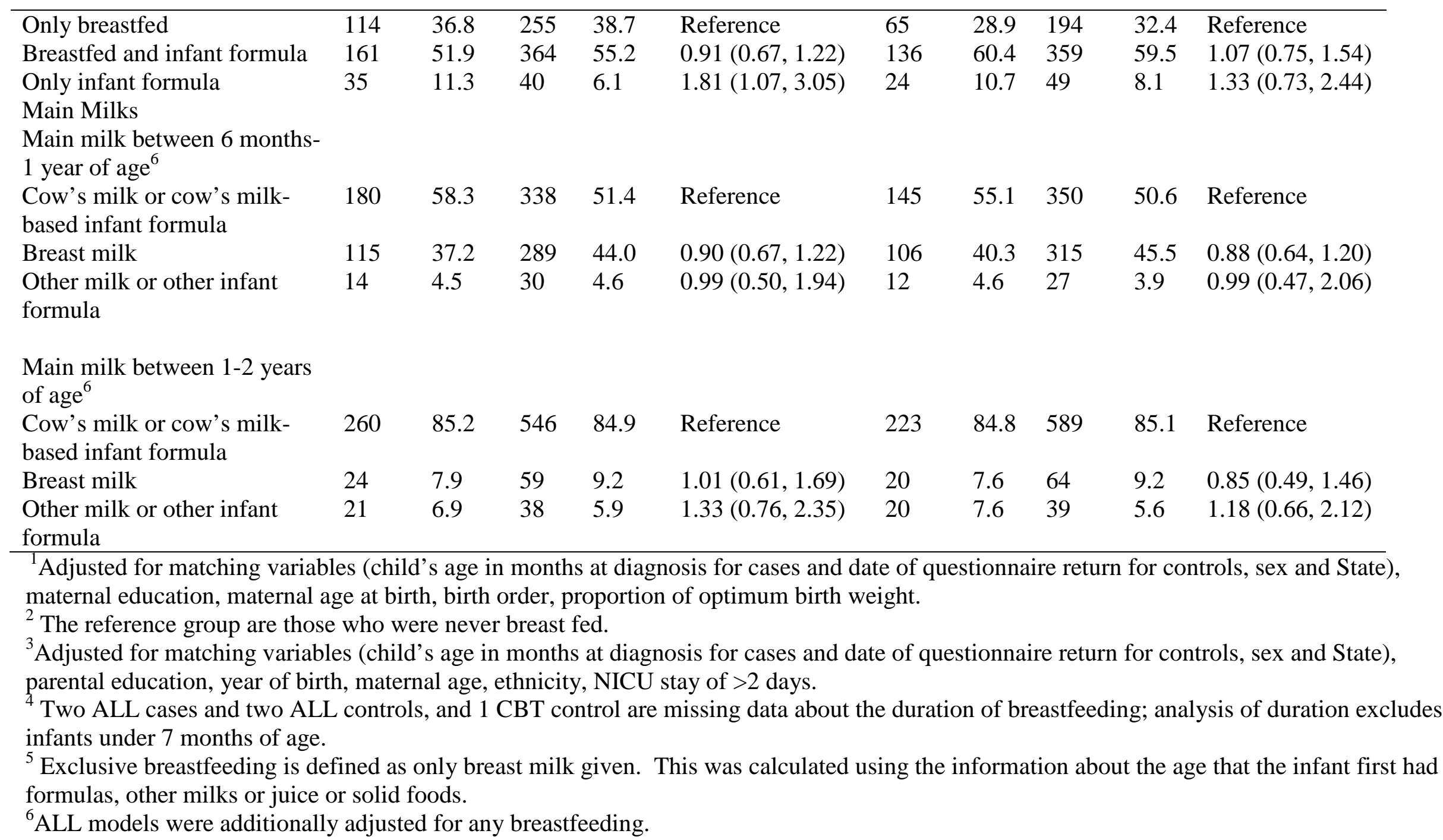


Table 3: Age of introduction of main foods and risk of childhood ALL and CBT

\begin{tabular}{|c|c|c|c|c|c|c|c|c|c|c|c|c|}
\hline \multirow{3}{*}{ Food } & \multicolumn{6}{|c|}{ ALL } & \multicolumn{6}{|c|}{ CBT } \\
\hline & \multicolumn{2}{|c|}{ case } & \multicolumn{2}{|c|}{ control } & \multirow[t]{2}{*}{$\mathrm{OR}^{1}$} & \multirow[t]{2}{*}{$95 \%$ CI } & \multicolumn{2}{|l|}{ case } & \multicolumn{2}{|c|}{ control } & \multirow[t]{2}{*}{$\mathrm{OR}^{2}$} & \multirow[t]{2}{*}{$95 \% \mathrm{CI}$} \\
\hline & $\mathrm{n}$ & $\%$ & $\mathrm{n}$ & $\%$ & & & $\mathrm{n}$ & $\%$ & $\mathrm{n}$ & $\%$ & & \\
\hline \multicolumn{13}{|l|}{ Any Food ${ }^{3}$} \\
\hline$\leq 4$ months & 165 & 56.5 & 362 & 57.2 & 1.00 & Referent & 111 & 41.3 & 322 & 47.4 & 1.00 & Referent \\
\hline$>4$ months & 126 & 43.2 & 270 & 42.7 & 1.09 & $0.82,1.46$ & 158 & 58.7 & 357 & 52.5 & 1.40 & $1.03,1.90$ \\
\hline $\begin{array}{l}\text { Not yet/not before } 2 \text { years } \\
\text { Any Solid }{ }^{4}\end{array}$ & 1 & 0.3 & 1 & 0.2 & & & 0 & 0 & 1 & 0.1 & & \\
\hline$\leq 4$ months & 160 & 54.2 & 355 & 56.0 & 1.00 & Referent & 108 & 40.1 & 314 & 46.2 & 1.00 & Referent \\
\hline$>4$ months & 134 & 45.4 & 278 & 43.8 & 1.14 & $0.86,1.52$ & 161 & 59.9 & 365 & 53.7 & 1.38 & $1.01,1.88$ \\
\hline $\begin{array}{l}\text { Not yet/not before } 2 \text { years } \\
\text { Cereal }\end{array}$ & 1 & 0.3 & 1 & 0.2 & & & 0 & 0 & 1 & 0.1 & & \\
\hline$\leq 5$ months & 182 & 60.1 & 411 & 63.8 & 1.00 & Referent & 146 & 53.3 & 377 & 55.0 & 1.00 & Referent \\
\hline$>5$ months & 114 & 37.6 & 222 & 34.5 & 1.23 & $0.92,1.64$ & 123 & 44.9 & 297 & 43.3 & 1.04 & $0.77,1.41$ \\
\hline $\begin{array}{l}\text { Not yet/not before } 2 \text { years } \\
\text { Vegetables }\end{array}$ & 7 & 2.3 & 11 & 1.7 & 1.42 & $0.53,3.83$ & 5 & 1.8 & 12 & 1.7 & 1.20 & $0.40,3.59$ \\
\hline$\leq 6$ months & 256 & 84.5 & 565 & 87.6 & 1.00 & Referent & 215 & 78.2 & 573 & 83.5 & 1.00 & Referent \\
\hline$>6$ months & 46 & 15.2 & 78 & 12.1 & 1.36 & $0.91,2.04$ & 60 & 21.8 & 110 & 16.0 & 1.31 & $0.91,1.90$ \\
\hline $\begin{array}{l}\text { Not yet/not before } 2 \text { years } \\
\text { Fruit }\end{array}$ & 1 & 0.3 & 2 & 0.3 & 1.13 & $0.10,13.23$ & 0 & 0 & 3 & 0.4 & & \\
\hline$\leq 6$ months & 238 & 78.5 & 521 & 80.7 & 1.00 & Referent & 199 & 72.4 & 537 & 78.4 & 1.00 & Referent \\
\hline$>6$ months & 63 & 20.8 & 123 & 19.0 & 1.13 & $0.79,1.60$ & 73 & 26.5 & 145 & 21.2 & 1.26 & $0.90,1.77$ \\
\hline $\begin{array}{l}\text { Not yet/not before } 2 \text { years } \\
\text { Fruit juice }\end{array}$ & 2 & 0.7 & 2 & 0.3 & 1.80 & $0.24,13.33$ & 3 & 1.1 & 3 & 0.4 & 2.05 & $0.35,12.06$ \\
\hline$\leq 7$ months & 163 & 54.5 & 319 & 49.5 & 1.00 & Referent & 103 & 37.6 & 266 & 38.9 & 1.00 & Referent \\
\hline$>7$ months & 115 & 38.5 & 260 & 40.4 & 0.88 & $0.65,1.19$ & 137 & 50.0 & 312 & 45.7 & 1.26 & $0.90,1.75$ \\
\hline $\begin{array}{l}\text { Not yet/not before } 2 \text { years } \\
\text { Meat/chicken }\end{array}$ & 21 & 7.0 & 65 & 10.1 & 0.64 & $0.37,1.10$ & 34 & 12.4 & 105 & 15.4 & 0.98 & $0.61,1.58$ \\
\hline$\leq 7$ months & 175 & 57.9 & 384 & 59.7 & 1.00 & Referent & 144 & 52.6 & 383 & 55.9 & 1.00 & Referent \\
\hline$>7$ months & 122 & 40.4 & 248 & 38.6 & 1.14 & $0.85,1.52$ & 122 & 44.5 & 290 & 42.3 & 1.03 & $0.77,1.39$ \\
\hline Not yet/not before 2 years & 5 & 1.7 & 11 & 1.7 & 1.08 & $0.36,2.32$ & 8 & 2.9 & 12 & 1.8 & 1.59 & $0.60,4.24$ \\
\hline
\end{tabular}




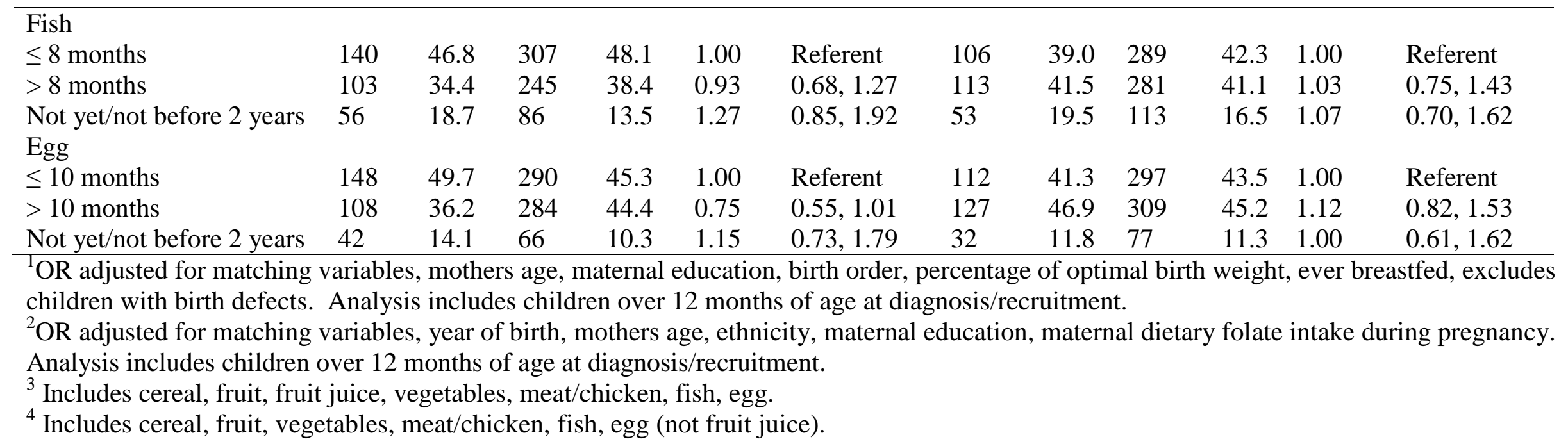


Table 4: Frequency of food types eaten between ages 1-2 and risk of childhood ALL and CBT

\begin{tabular}{llllllll}
\hline \multirow{2}{*}{ Food Group } & \multicolumn{9}{c}{ ALL } & \multicolumn{3}{c}{ CBT } \\
\cline { 2 - 8 } & Times/day & $\begin{array}{l}\text { N case/ } \\
\text { control }\end{array}$ & OR $^{1}$ & $95 \%$ CI & $\begin{array}{l}\text { N case/ } \\
\text { control }\end{array}$ & OR $^{2}$ & $95 \%$ CI \\
\hline Cereals $^{3}$ & $0-2.7$ & $91 / 212$ & 1.00 & Referent & $98 / 245$ & 1.00 & Referent \\
& $>2.6-3.6$ & $115 / 197$ & 1.40 & $0.99,1.97$ & $98 / 245$ & 1.12 & $0.79,1.58$ \\
& $>3.6$ & $96 / 231$ & 1.00 & $0.71,1.42$ & $87 / 202$ & 1.10 & $0.77,1.58$ \\
Fruits $^{4}$ & & & & & & & \\
& $0-1.7$ & $105 / 217$ & 1.00 & Referent & $104 / 234$ & 1.00 & Referent \\
& $>1.7-2.6$ & $78 / 200$ & 0.86 & $0.60,1.23$ & $93 / 261$ & 0.87 & $0.62,1.23$ \\
Vegetables $^{5}$ & $>2.6$ & $121 / 222$ & 1.18 & $0.85,1.65$ & $86 / 197$ & 1.10 & $0.76,1.59$ \\
& & & & & & & \\
& $0-1.1$ & $125 / 232$ & 1.00 & Referent & $100 / 247$ & 1.00 & Referent \\
Dairy products $^{6}$ & $>1.1-2.0$ & $125 / 286$ & 0.86 & $0.63,1.17$ & $123 / 295$ & 1.07 & $0.77,1.49$ \\
& $>2.0$ & $54 / 124$ & 0.86 & $0.58,1.29$ & $60 / 150$ & 0.99 & $0.66,1.47$ \\
& $0-2.1$ & $89 / 218$ & 1.00 & Referent & $105 / 236$ & 1.00 & Referent \\
& $>2.1-3.7$ & $111 / 212$ & 1.21 & $0.86,1.71$ & $100 / 225$ & 1.00 & $0.71,1.41$ \\
Meat/fish/chicken/egg $^{5}$ & & $102 / 212$ & 1.13 & $0.80,1.61$ & $77 / 230$ & 0.79 & $0.55,1.14$ \\
& $0-0.7$ & $100 / 222$ & 1.00 & Referent & $108 / 243$ & 1.00 & Referent \\
& $>0.7-1.1$ & $93 / 230$ & 0.96 & $0.68,1.35$ & $91 / 251$ & 0.91 & $0.64,1.28$ \\
& $>1.1$ & $110 / 191$ & 1.39 & $0.98,1.96$ & $83 / 198$ & 0.93 & $0.65,1.34$ \\
\hline
\end{tabular}

\footnotetext{
${ }^{1}$ Adjusted for matching variables (child's age at IFQ return, sex, state of residence), maternal age, maternal education, birth order, POBW, child ever breast fed.

${ }^{2}$ Adjusted for matching variables (child's age, sex, state of residence), child's year of birth, maternal age, maternal education, maternal dietary folate intake, child's ethnicity.

${ }^{3}$ Group includes breakfast cereal, bread, rice, crackers, rusks, pasta.

${ }^{4}$ Group includes stewed/pureed fruit, citrus fruit, other fruits, fruit juice.

${ }^{5}$ Group includes raw vegetables, cooked green and other vegetables (except potato).

${ }^{6}$ Group includes cow or goats milk, cheese, yoghurt, custard.
} 
Supplemental Table 1: Breastfeeding and formula feeding and risk of ALL and CBT by subtypes.

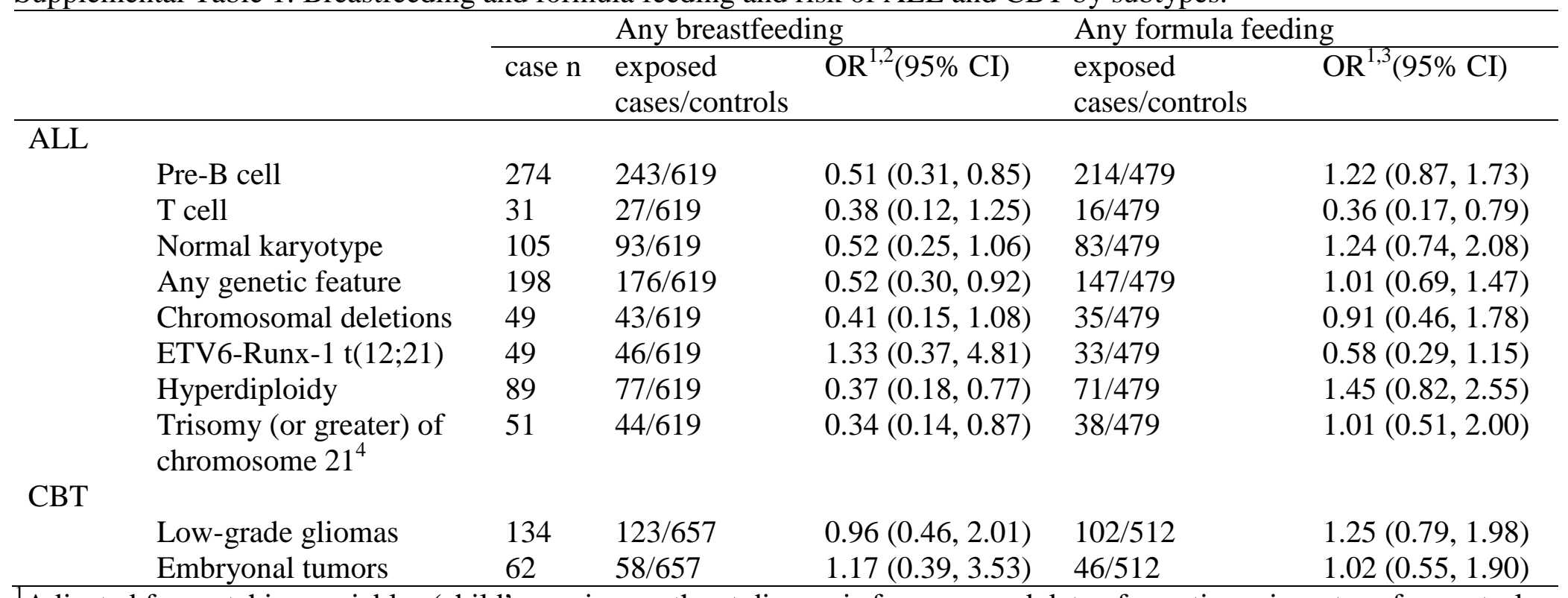

\footnotetext{
${ }^{1}$ Adjusted for matching variables (child's age in months at diagnosis for cases and date of questionnaire return for controls, sex and State), maternal education, maternal age at birth, birth order, proportion of optimum birth weight.

${ }^{2}$ The reference group are those who were never breast fed. Excludes children under 7 months age.

${ }^{3}$ The reference group are those who were never formula fed. Excludes children under 7 months age.

${ }^{4}$ Refers to somatic (not constitutive) changes in tumor cells; children with Down syndrome were excluded from the analysis.
} 
Supplemental Table 2: Correlations (Pearson's r) between the ages of introduction of key solid foods

\begin{tabular}{|l|l|l|l|l|l|l|l|}
\hline & Cereal & Fruit & Vegetables & $\begin{array}{l}\text { Meat or } \\
\text { chicken }\end{array}$ & Fish & Fruit juice & Egg \\
\hline ALL cases and controls & & & & & & & \\
\hline Cereal & 1.00 & $0.48^{* *}$ & $0.49^{* *}$ & $0.41^{* *}$ & $0.19^{* *}$ & $0.24^{* *}$ & $0.24^{* *}$ \\
\hline Fruit & & 1.00 & $0.78^{* *}$ & $0.54^{* *}$ & $0.30^{* *}$ & $0.27^{* *}$ & $0.29^{* *}$ \\
\hline Vegetables & & & 1.00 & $0.62^{* *}$ & $0.31^{* *}$ & $0.28^{* *}$ & $0.31^{* *}$ \\
\hline Meat or chicken & & & & 1.00 & $0.45^{* *}$ & $0.23^{* *}$ & $0.35^{* *}$ \\
\hline Fish & & & & & 1.00 & $0.15^{* *}$ & $0.40^{* *}$ \\
\hline Fruit juice & & & & & & 1.00 & $0.30^{* *}$ \\
\hline Egg & & & & & & & \\
\hline CBT cases and controls & & & & & & & 1.00 \\
\hline Cereal & 1.00 & $0.36^{* *}$ & $0.44^{* *}$ & $0.38^{* *}$ & $0.14^{* *}$ & $0.24^{* *}$ & $0.19^{* *}$ \\
\hline Fruit & & 1.00 & $0.70^{* *}$ & $0.50^{* *}$ & $0.29^{* *}$ & $0.23^{* *}$ & $0.32^{* *}$ \\
\hline Vegetables & & & $1.00^{* *}$ & $0.57^{* *}$ & $0.29^{* *}$ & $0.26^{* *}$ & $0.32^{* *}$ \\
\hline Meat or chicken & & & & 1.00 & $0.48^{* *}$ & $0.21^{* *}$ & $0.38^{* *}$ \\
\hline Fish & & & & & 1.00 & $0.09^{*}$ & $0.47^{* *}$ \\
\hline Fruit juice & & & & & & 1.00 & $0.19^{* *}$ \\
\hline Egg & & & & & & & 1.00 \\
\hline
\end{tabular}

$* \mathrm{P}$ values $<0.01 * * \mathrm{P}$ values $<0.001$ 
Supplemental Table 3: Odds ratios and 95\% confidence intervals for the risk of ALL and CBT associated with the level of daily dietary folate equivalents between $1-2$ years of age

\begin{tabular}{|c|c|c|c|c|c|c|c|}
\hline & & & & & & & \\
\hline & $\begin{array}{l}\text { Cases }^{1} \\
\mathrm{n}=305\end{array}$ & $\begin{array}{l}\text { Controls }^{1} \\
n=645\end{array}$ & & & $\begin{array}{l}\text { Cases }^{1} \\
n=271\end{array}$ & $\begin{array}{l}\text { Controls }^{1} \\
\mathrm{n}=671\end{array}$ & \\
\hline $\begin{array}{l}\text { Daily dietary folate } \\
\text { equivalents }(\mu \mathrm{g})\end{array}$ & n (\%) & n (\%) & $\mathrm{OR}^{2,3}(95 \% \mathrm{CI})$ & $\begin{array}{l}\text { Daily dietary folate } \\
\text { equivalents }(\mu g)\end{array}$ & n (\%) & n (\%) & $\mathrm{OR}^{3,4}(95 \% \mathrm{CI})$ \\
\hline 0 to 97 & $56(18.4)$ & $116(18.0)$ & Reference & 0 to 106.5 & $57(21.0)$ & 135 (20.1) & Reference \\
\hline$>97-138$ & 66 (21.6) & 135 (20.9) & $1.00(0.64,1.56)$ & $>106.5$ to 153.0 & $56(20.7)$ & $136(20.3)$ & $1.03(0.65,1.64)$ \\
\hline$>138-181$ & $66(21.6)$ & $130(20.2)$ & $1.04(0.66,1.62)$ & $>153.0$ to 193.9 & $52(19.2)$ & 130 (19.4) & $1.05(0.65,1.68)$ \\
\hline$>181-228$ & $55(18.0)$ & $133(20.6)$ & $0.82(0.51,1.30)$ & $>193.9$ to 237.5 & $61(22.5)$ & 135 (20.1) & $1.31(0.82,2.07)$ \\
\hline$>228$ & $62(20.3)$ & 131 (20.3) & $0.95(0.60,1.50)$ & $>237.5$ & 45 (16.6) & $135(20.1)$ & $1.02(0.62,1.67)$ \\
\hline
\end{tabular}

${ }^{1}$ Only subjects with full dietary information aged over 1 year of age are included in these analyses

${ }^{2}$ Adjusted for matching variables (child's age in months at diagnosis for cases and date of questionnaire return for controls, sex and State), maternal education, maternal age at birth, birth order, proportion of optimum birth weight and ever breast fed.

${ }^{3}$ The reference group are those in the lowest intake quintile.

${ }^{4}$ Adjusted for matching variables (child's age in months at diagnosis for cases and date of questionnaire return for controls, sex and State), parental education, child's year of birth, ethnicity, maternal folic acid supplementation 1 month prior to pregnancy, maternal alcohol consumption during pregnancy, maternal dietary folate intake during pregnancy. 
Supplemental Table 4: Odds ratios and 95\% confidence intervals for the risk of ALL associated with having vitamins and other supplements until the age of two years

\begin{tabular}{|c|c|c|c|c|c|c|}
\hline & \multicolumn{2}{|c|}{ ALL } & \multicolumn{4}{|c|}{ CBT } \\
\hline & $\begin{array}{l}\text { Cases } \\
\mathrm{n}=316\end{array}$ & $\begin{array}{l}\text { Controls } \\
\mathrm{n}=663\end{array}$ & & $\begin{array}{l}\text { Cases } \\
n=292\end{array}$ & $\begin{array}{l}\text { Controls } \\
n=728\end{array}$ & \\
\hline & n (\%) & n (\%) & $\mathrm{OR}^{1,2}(95 \% \mathrm{CI})$ & n (\%) & $\mathrm{n}(\%)$ & $\mathrm{OR}^{2,3}(95 \% \mathrm{CI})$ \\
\hline Any supplements & & & & & & \\
\hline No & 288 (91.1) & 589 (88.8) & Reference & $254(87.0)$ & $627(86.1)$ & Reference \\
\hline Yes & $28(8.9)$ & $74(11.2)$ & $0.81(0.51,1.29)$ & $38(13.0)$ & 101 (13.9) & $0.99(0.65,1.50)$ \\
\hline Multivitamin $^{4}$ & $24(7.7)$ & $46(7.2)$ & $1.10(0.65,1.85)$ & $24(8.6)$ & $59(8.6)$ & $1.06(0.63,1.79)$ \\
\hline Folate & $7(2.4)$ & $13(2.2)$ & $1.04(0.40,2.70)$ & $16(5.9)$ & $26(4.0)$ & $1.43(0.73,2.80)$ \\
\hline B12 & $6(2.0)$ & $17(2.8)$ & $0.69(0.26,1.80)$ & 17 (6.3) & $27(4.1)$ & $1.52(0.79,2.93)$ \\
\hline Vitamin C & 18 (5.9) & $30(4.8)$ & $1.29(0.70,2.38)$ & $11(4.2)$ & $43(6.4)$ & $0.68(0.34,1.36)$ \\
\hline Vitamin A & $16(5.3)$ & $21(3.4)$ & $1.64(0.84,3.24)$ & $8(3.1)$ & $30(4.6)$ & $0.73(0.32,1.66)$ \\
\hline Iron & $18(5.9)$ & $32(5.2)$ & $1.14(0.62,2.09)$ & $27(9.6)$ & $56(8.2)$ & $1.25(0.75,2.08)$ \\
\hline
\end{tabular}

${ }^{1}$ Adjusted for matching variables (child's age in months at diagnosis for cases and date of questionnaire return for controls, sex and State), maternal education, maternal age at birth, birth order, proportion of optimum birth weight and ever breast fed.

${ }^{2}$ The reference group are those who did not have any vitamins, minerals or other dietary supplements before the age of two years.

${ }^{3}$ Adjusted for matching variables, year of birth, parental education, child's ethnicity, maternal alcohol consumption during pregnancy, maternal use of folic acid supplements 1 month before pregnancy.

${ }^{4}$ For ALL, all these products and only these contained B6. For CBT, only one child had B6 that was not part of a multivitamin. 